\title{
Extinction filters mediate the global effects of habitat fragmentation on animals
}

Authors: Matthew G. Betts*1, Christopher Wolf*1, Marion Pfeifer ${ }^{2}$, Cristina Banks-Leite ${ }^{3}$, Victor Arroyo-Rodríguez ${ }^{4}$, Danilo Bandini Ribeiro ${ }^{5}$, Jos Barlow ${ }^{6}$, Felix Eigenbrod7 Deborah Faria ${ }^{8}$, Robert J. Fletcher Jr. ${ }^{9}$, Adam S. Hadley ${ }^{1}$, Joseph E. Hawes ${ }^{10}$, Robert D. Holt $^{11}$, Brian Klingbeil ${ }^{12}$, Urs Kormann ${ }^{1,13}$, Luc Lens ${ }^{14}$, Taal Levi ${ }^{1}$, Guido. F. MedinaRangel ${ }^{15}$, Stephanie L. Melles ${ }^{16}$, Dirk Mezger ${ }^{17}$, José Carlos Morante-Filho ${ }^{8,18}$, C. David L. Orme ${ }^{3}$, Carlos A. Peres ${ }^{19}$, Benjamin T. Phalan ${ }^{20}$, Anna Pidgeon ${ }^{21}$, Hugh Possingham ${ }^{22}$, William J. Ripple1, Eleanor M. Slade ${ }^{23}$, Eduardo Somarriba ${ }^{24}$, Joseph A. Tobias ${ }^{3}$, Jason M. Tylianakis ${ }^{25}$, J. Nicolás Urbina-Cardona ${ }^{26}$, Jonathon J. Valente ${ }^{1,27}$, James I. Watling ${ }^{28}$, Konstans Wells ${ }^{29}$, Oliver R. Wearn ${ }^{30}$, Eric Wood ${ }^{31}$, Richard Young ${ }^{32}$, Robert M. Ewers ${ }^{3}$

*Corresponding authors (contributed equally); Email: matt.betts@oregonstate.edu, wolfch@oregonstate.edu

Affiliations:

${ }^{1}$ Forest Biodiversity Research Network, Dept. of Forest Ecosystems and Society, Oregon State University, Corvallis, Oregon, 97331

${ }^{2}$ School of Biology, Newcastle University, Newcastle Upon Tyne NE1 7RU, UK

${ }^{3}$ Imperial College London, Silwood Park Campus, Buckhurst Road, Ascot SL5 7PY, UK

${ }^{4}$ Instituto de Investigaciones en Ecosistemas y Sustentabilidad, Universidad Nacional Autónoma de México (UNAM), campus Morelia, Antigua Carretera

Patzcuaro No. 8701, Ex-Hacienda de San José de la Huerta, 58190 Morelia, Michoacán, Mexico

Instituo de Biociências, Universidade Federal de Mato Grosso do Sul, Caixa Postal 549, 79070-900 Campo Grande, Brasil

'Lancaster Environment Centre, Lancaster University, Lancaster LA1 4YQ, UK

${ }^{7}$ Geography and Environmental Sciences, University of Southampton, UK

${ }^{8}$ Applied Conservation Ecology Lab, Programa de Pós-graduação em Ecologia e Conservação, da Biodiversidade, Universidade Estadual de Santa Cruz, Rodovia Ilhéus-Itabuna, km 16, Salobrinho, 45662-000 Ilhéus, Bahia, Brazil

${ }^{9}$ Department of Wildlife Ecology and Conservation at the University of Florida, Gainesville, FL 32611-8525, USA

${ }^{10}$ Applied Ecology Research Group, School of Life Sciences, Anglia Ruskin University, Cambridge, CB1 1PT, UK

${ }^{11}$ Dept. of Biology, University of Florida, Gainesville, FL 32611-8525, USA

${ }^{12}$ School of Forestry and Wildlife Sciences, Auburn University, Auburn AL; brian.klingbeil@auburn.edu

${ }^{13}$ Swiss Ornithological Institute, Sempach, Switzerland, Division of Forest Sciences, School of Agricultural, Forest and Food Sciences HAFL

${ }^{14}$ Ghent University, Dept. of Biology, K.L. Ledeganckstraat 35, B-9000 Gent, Belgium

${ }^{15}$ Groupo de Biodiversidad y Conservación, Reptiles, Instituto de Ciencias Naturales, Universidad Nacional de Colombia, Ciudad Universitaria, Edificio 425 Bogotá, Distrito Capital, Colombia

${ }^{16}$ Department of Chemistry and Biology, Ryerson University, 350 Victoria Street, Toronto, ON M5B 2K3, Canada

${ }^{17}$ Department of Science and Education, Field Museum of Natural History, Chicago, IL, U.S.A.

${ }^{18}$ Departamento de Ciências Biológicas, Universidade Estadual de Feira de Santana, Avenida Transnordestina, s/n - Novo Horizonte, 44036-900 Feira de Santana, Bahia, Brazil.

${ }^{19}$ Center for Ecology, Evolution \& Conservation, School of Environmental Sciences, University of East Anglia, Norwich NR4 7TJ, United Kingdom

${ }^{20}$ Instituto de Biologia, Universidade Federal da Bahia, Salvador, 40170-115 Bahia, Brazil

${ }^{21}$ University of Wisconsin - Madison, Department of Forest and Wildlife Ecology, 1630 Linden Drive, Madison, WI 53706, USA

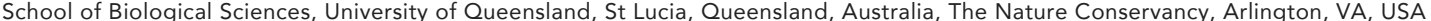

${ }^{23}$ Asian School of the Environment, Nanyang Technological University, 62 Nanyang Dr, Singapore 637459

${ }^{24}$ Centro Agronómico Tropical de Investigación y Enseñanza. Turrialba, Costa Rica.

${ }^{25}$ School of Biological Sciences, University of Canterbury, Private bag 4800, Christchurch 8140, New Zealand

${ }^{26}$ Department of Ecology and Territory, School of Rural and Environmental Studies, Pontificia Universidad Javeriana, Bogota, Colombia.

${ }^{27}$ Smithsonian Conservation Biology Institute, Migratory Bird Center, National Zoological Park, Washington, DC 20013, USA.

${ }^{28}$ Department of Biology, John Carroll University, University Heights, OH 44118 USA

${ }^{29}$ Department of Biosciences, Swansea University, Swansea SA2 8PP, Wales, UK

${ }^{30}$ Institute of Zoology, Zoological Society of London, Regent's Park, London, NW1 4RY, UK

${ }^{31}$ Department of Biological Sciences, California State University Los Angeles, 5151 State University Drive, Los Angeles, California 90032, USA

${ }^{32}$ Durrell Wildlife Conservation Trust, Les Augres Manor, Trinity, Jersey, JE3 5BP, UK 
Abstract: Habitat loss is the primary driver of biodiversity decline worldwide, but the effects of fragmentation (i.e., the spatial arrangement of remaining habitat) are debated. We tested the hypothesis that forest fragmentation sensitivity - affected by avoidance of habitat edges - should be driven by historical exposure, and therefore species' evolutionary responses, to disturbance. Using a database containing 73 datasets worldwide (4,489 animal species), we found that the proportion of fragmentation-sensitive species was nearly three times higher in regions with low 65 versus high rates of historical disturbance (i.e., fires, glaciation, hurricanes, and deforestation). These disturbances coincide with a latitudinal gradient in which sensitivity increases six-fold at low versus high latitudes. We conclude that conservation efforts to limit edges created by fragmentation will be most important in the world's tropical forests.

One Sentence Summary: Animal species that have evolved, and survived, in lowdisturbance environments are more sensitive to forest fragmentation. 


\section{Main Text:}

Global biodiversity loss is occurring at over 100 times the background rate (1) and there is general consensus that most species declines can be attributed to habitat loss $(2,3)$. Nevertheless, the degree to which habitat fragmentation, defined as the spatial arrangement of remaining habitat, influences biodiversity loss has been a source of contention for over 40 years (4-7). Reconciling this debate is important to conservation planning, which can entail designing the configuration of landscapes as well as spatially prioritizing areas for conservation (8). Forest fragmentation is particularly pressing given that $70 \%$ of Earth's remaining forest is within $1 \mathrm{~km}$ of the forest edge (9), and that fragmentation of the world's currently most intact forest landscapes - the tropics - is predicted to accelerate over the coming five decades (10).

Central to the fragmentation debate is the variation across taxa and regions in species responses to fragmentation and edge effects in particular $(6,11,12)$. It is well known that life-history and other ecological traits mediate species' responses to habitat edges (13), but the degree to which there are predictable geographical patterns in species' sensitivity has yet to be quantified across $90 \quad$ multiple taxa at the global scale.

Species' evolutionary histories can shape their capacity to deal with novel stressors. The 'extinction filter' hypothesis predicts that species that have evolved, and survived, in highdisturbance environments should be more likely to persist in the face of new disturbances, 95 including those of habitat loss and fragmentation (14). Further, more frequent disturbances could act as a barrier to sensitive species, preventing them from colonizing disturbance-prone regions. Disturbances often create edges, and in environments with frequent and large-scale disturbances, 
persistent species are more likely to be adapted to ubiquitous edge habitats. The extinction filter hypothesis is at least several decades old, and has been suggested to apply in forest $(15,16)$ and grassland systems (14). Both natural (e.g., wildfires, glaciation) and anthropogenic disturbances (e.g., logging, burning, hunting) are thought to exert such evolutionary pressures (14). Nevertheless, there has been no global test of whether historical disturbance regimes can explain fragmentation effects.

105 We used 73 datasets worldwide containing 4,489 species (from four major taxa: arthropods: 2,682; birds: 1,260; herptiles (reptiles and amphibians): 282, mammals: 265 (Figs. 1 \& S1, Tables S1 \& S2) to provide a global test of the extinction filter hypothesis in forest ecosystems (17). In the presence of an extinction filter, species inhabiting a 'filtered' landscape with high levels of disturbances over historical (evolutionary) time-scales should be resilient to new

110 disturbances - either because sensitive species have been driven locally extinct or because extant species have adapted to disturbance. Either mechanism would lead to a reduced prevalence of fragmentation-sensitive species in regions of the globe where disturbance has been historically common.

115 We used a recently developed approach to quantify the landscape-scale impacts of forest edges on biodiversity $(11,13)$. By definition, habitat fragmentation for a given habitat amount leads to more, smaller patches, with a greater proportion of edge. We focus on landscape-scale variation in edge effects rather than the number of patches, because edge effects have long been known to have widespread effects on biodiversity (13) and the approach we use comprehensively captures 
the process of fragmentation at the landscape-scale [see supplementary materials (17), Figs. S2 $\&$ S3].

These data and methodology have been documented extensively elsewhere (13), so we present a brief overview relevant to our analysis. Each dataset contains a set of sample points within a fragmented forest region where abundances of one or more species from major taxonomic groups were sampled. We quantified two key aspects of edge effects: edge influence across the region, and edge sensitivity of species. We quantified edge influence $(E I)$ surrounding sample points based on variation in percentage of forest cover [see supplementary materials (17) and Pfeifer et al. (13) for details]. This metric accounts for the cumulative effects of multiple edges (including edge shape and patch size) that magnify the realized impact of edges on species. Edge sensitivity $(S)$ is a population-specific measure of fragmentation sensitivity that ranges from 0.0 (no edge response) to 1.0 (high edge avoidance or preference). Because $S$ does not distinguish between forest and matrix species and between edge avoidance and edge preference, we additionally used abundance, percentage tree cover within $30 \mathrm{~m}$ of sample points, and $E I$ to 135 classify species as forest, non-forest matrix, or generalist habitat users and 'core,' 'edge,' or 'no preference' [(17) and Fig. S4]. We did so by simulating sets of example abundances in each category (e.g., 'forest core') and then using a naïve Bayes classifier to estimate the most likely category for each actual species based on abundance versus point cover and EI relationships. By definition, forest core species are those that are restricted to forest areas that are distant from the edge, hence are sensitive to fragmentation of large patches into smaller ones (Figs. S2 \& S3). We used this classification as the basis for our statistical models, focusing both on the probability of forest species being classified as core and the probability of species being classified as forest, 
matrix, or generalist. For each study site, we assembled previously available data on forest fire severity (19), whether or not its location was glaciated in the last glacial maximum (20), whether 145 or not it experienced tropical storms (21), and if historical anthropogenic forest loss exceeded $50 \%(3)$ [Fig. 1, (17)].

Across all species combined, we found strong support for the extinction filter hypothesis explaining geographically variable sensitivity to forest edge. The odds of forest species being 150 classified as forest core were 79.0\% [95\% CI: $65.9 \%, 87.0 \%]$ lower in study regions that have experienced historically severe disturbances (Fig. 2, p $<0.001$, Table S3). A substantial 51.3\% of forest species tended to avoid edges in low-disturbance regions, while only $18.1 \%$ of forest species in high-disturbance regions avoided edges (Fig. 2). Edge-sensitive species are therefore largely absent from communities in historically disturbed locations, suggesting they have either

155 disappeared from these regions or adapted to become less edge sensitive. This result was particularly strong for arthropods and birds, and in the same direction for herptiles and mammals, though non-significant, likely owing to lower sample sizes. Results were stronger still when we considered the proportion of forest species as a function of disturbance severity. The odds of a species being forest-associated versus being associated with other habitats were $729 \%$ [95\% CI: 608\%, 891\%] higher in low-disturbance versus high-disturbance regions (Fig. S5, Table S4).

Edge sensitivity $(S)$ of forest core species tended to be 1.16 times higher in low $(S=0.660 \pm 0.004$ $\left.S E_{\bar{x}}\right)$ versus high $(\mathrm{S}=0.568 \pm 0.004)$ disturbance regions. This effect size is considerable; species with values of $S>0.75$ are only found within the forest interior far away from edges, whereas 165 forest species with $S=0.5$ are abundant up to the edge (13). In addition, historical anthropogenic 
forest loss alone was substantially less effective at predicting the proportion of core species than either the combination of historical disturbances, or natural disturbance alone (Table S3). Thus, evolutionary responses and patterns of extinction in of forest species in high-disturbance regions is not driven solely by anthropogenic habitat loss and fragmentation.

The effects of disturbance on edge influence sensitivity and the proportion of forest core species are unlikely to be an artifact of under-sampling in high-disturbance regions (Fig. S6). Also, these results were robust to other potential confounding variables - phylogenetic relatedness (Fig. S7), migratory behavior (Table S5), geographic range size (Table S6), and distance to range edge

175 (Table S6). Importantly, the strong disturbance effect could not be reproduced when species were categorized using forest amount alone ( 6 ), indicating that our findings relate primarily to fragmentation in addition to landscape-scale forest loss (Tables S7 \& S8). The disturbance effect generally remained after statistically accounting for absolute latitude (Table S9); the proportion of forest core species declined roughly six-fold, and the proportion of forest-associated species 180 declined 1.5-fold, over the entire latitudinal gradient observed (0.7 - 51.8 degrees) (Figs. 3, S8 S9). Tropical species have been confronted with less historical disturbance (Fig. 1b) and therefore tend to be more edge sensitive, and more likely to be associated with forest (Table S4, Fig. S8).

185 The extinction filter hypothesis can be generalized beyond forest species to predict that in areas typified by large-scale historical disturbances, we should see a greater proportion of species that have evolved with non-forest land-cover types including disturbed habitats (hereafter the 'matrix'). For example, a wide range of species in the Pacific Northwestern USA - where stand- 
replacing crown fires are common- are associated with early successional ecosystems (22). Our data supported this prediction; the odds of species using matrix habitat relative to using forest habitat were estimated to be $644 \%$ higher in high disturbance regions than in low disturbance regions (95\% CI: [523\%, 788\%]; Fig. S5, Table S4). The proportion of matrix species also strongly increased with latitude (Fig. S9, Table S4).

195 Our results support the extinction filter hypothesis; climatic, ecological and anthropogenic disturbances have already filtered out many of the species that would be more susceptible to forest edges and the process of fragmentation caused by deforestation (16). Proportions of forest core species are substantially greater in regions that have not experienced large-scale historical disturbances. This effect results in a latitudinal gradient in fragmentation sensitivity, and helps to 200 explain surprising rarity of extinctions following recent anthropogenic disturbance in Europe and eastern North America (23). Species that were strongly sensitive to disturbance-created edges have likely either undergone local extinction or adapted to repeated glaciation or historical land clearance.

205 Our results partly reconcile the debate about the conservation importance of fragmentation and its effect on biodiversity $(6,7)$. Many studies finding reduced fragmentation effects were conducted in already denuded landscapes (24), in locations with stand-replacing disturbance (glaciers, fire, 25) and at high latitudes, which experienced glacial advances and retreats (26). Conversely, studies finding strong, negative fragmentation effects are often from the tropics 210 where broad-scale disturbance is rarer (27) or for matrix-associated temperate zone species which are adapted to unfragmented but disturbed habitat $(28,29)$. Exceptions to this general 
pattern do, of course, exist $(30,31)$. Further, we caution that temperate species are not necessarily robust to anthropogenic change of other types, and synergistic effects of stressors may pose novel threats. For instance, climate change may interact with habitat loss and

215 fragmentation to reduce species' capacity to adapt (32). Nevertheless, our data highlight a strong underlying pattern that has the potential to explain why fragmentation studies are known for generating such widely variable results. It will be essential to tie our broad-scale analyses to the analysis of the mechanistic underpinnings of fragmentation sensitivity to better generalize across biomes and taxa.

These results indicate that conservation actions designed to mitigate edge-driven fragmentation effects can be tailored to the particular regions most likely to host sensitive species, rather than applying simple rules to the entire globe. Regions in temperate zones with greater historical disturbance might focus more on conserving mature forest habitat, regardless of its spatial 225 configuration (6). On the other hand, efforts to reduce forest fragmentation should be concentrated in regions with low historical disturbance, particularly tropical forests (13) especially those in biodiversity hotspots (33) - where fragmentation continues at a rapid rate and poses the greater extinction risk. 


\section{References}

1. G. Ceballos et al., Accelerated modern human-induced species losses: Entering the sixth mass extinction. Science Advances. 1, e1400253 (2015).

2. T. Newbold et al., Has land use pushed terrestrial biodiversity beyond the planetary boundary? A global assessment. Science. 353, 288-291 (2016).

3. M. G. Betts et al., Global forest loss disproportionately erodes biodiversity in intact landscapes. Nature. 547, 441-444 (2017).

4. J. M. Diamond, The island dilemma: lessons of modern biogeographic studies for the design of natural reserves. Biological conservation. 7, 129-146 (1975).

5. D. S. Simberloff, L. G. Abele, Island biogeography theory and conservation practice. Science. 191, 285-286 (1976).

6. L. Fahrig, Ecological responses to habitat fragmentation per se. Annual Review of Ecology, Evolution, and Systematics. 48, 1-23 (2017).

7. R. J. Fletcher Jr et al., Is habitat fragmentation good for biodiversity? Biological conservation. 226, 9-15 (2018).

245 8. S. B. Carvalho et al., Spatial conservation prioritization of biodiversity spanning the evolutionary continuum. Nature ecology \& evolution. 1, 0151 (2017).

9. N. M. Haddad et al., Habitat fragmentation and its lasting impact on Earth's ecosystems. Science Advances. 1, e1500052 (2015).

10. F. Taubert et al., Global patterns of tropical forest fragmentation. Nature. 554, 519 (2018).

250 11. L. Ries, R. J. Fletcher Jr, J. Battin, T. D. Sisk, Ecological responses to habitat edges: mechanisms, models, and variability explained. Annu. Rev. Ecol. Evol. Syst. 35, 491-522 (2004).

12. L. R. Prugh, K. E. Hodges, A. R. Sinclair, J. S. Brashares, Effect of habitat area and isolation on fragmented animal populations. Proceedings of the National Academy of Sciences. 105, 20770-20775 (2008).

13. M. Pfeifer et al., Creation of forest edges has a global impact on forest vertebrates. Nature. 551, 187 (2017).

14. A. Balmford, Extinction filters and current resilience: the significance of past selection pressures for conservation biology. Trends in Ecology \& Evolution. 11, 193-196 (1996).

15. A. J. Hansen, D. L. Urban, Avian response to landscape pattern: the role of species' life histories. Landscape Ecology. 7, 163-180 (1992).

16. P. Drapeau, M.-A. Villard, A. Leduc, S. J. Hannon, Natural disturbance regimes as templates for the response of bird species assemblages to contemporary forest management. Diversity and Distributions. 22, 385-399 (2016).

17. See supplementary materials.

18. M. Pfeifer et al., BIOFRAG-a new database for analyzing BIO diversity responses to forest FRAG mentation. Ecology and Evolution. 4, 1524-1537 (2014). 
19. S. Lavorel, M. D. Flannigan, E. F. Lambin, M. C. Scholes, Vulnerability of land systems to fire: Interactions among humans, climate, the atmosphere, and ecosystems. Mitigation and Adaptation Strategies for Global Change. 12, 33-53 (2007).

20. N. Ray, J. Adams, A GIS-based vegetation map of the world at the last glacial maximum (25,000-15,000 BP). Internet archaeology. 11 (2001).

21. Met Office, Location of tropical cyclones. Met Office (2018), (available at https://www.metoffice.gov.uk/learning/storms/tropical-cyclones/location).

22. M. E. Swanson et al., The forgotten stage of forest succession: early-successional ecosystems on forest sites. Frontiers in Ecology and the Environment. 9, 117-125 (2011).

23. S. L. Pimm, G. J. Russell, J. L. Gittleman, T. M. Brooks, The future of biodiversity. Science. 269, 347 (1995).

24. M. K. Trzcinski, L. Fahrig, G. Merriam, Independent effects of forest cover and fragmentation on the distribution of forest breeding birds. Ecological Applications. 9, 586-593 (1999).

25. K. McGarigal, W. C. McComb, Relationships between landscape structure and breeding birds in the Oregon Coast Range. Ecological monographs. 65, 235-260 (1995).

26. F. K. Schmiegelow, C. S. Machtans, S. J. Hannon, Are boreal birds resilient to forest fragmentation? An experimental study of short-term community responses. Ecology. 78, 1914-1932 (1997).

27. J. Barlow et al., Anthropogenic disturbance in tropical forests can double biodiversity loss from deforestation. Nature. 535, 144 (2016).

28. E. I. Damschen, N. M. Haddad, J. L. Orrock, J. J. Tewksbury, D. J. Levey, Corridors increase plant species richness at large scales. Science. 313, 1284-1286 (2006).

29. I. Hanski et al., Ecological and genetic basis of metapopulation persistence of the Glanville fritillary butterfly in fragmented landscapes. Nature communications. 8, 14504 (2017).

30. R. M. Ewers, S. Thorpe, R. K. Didham, Synergistic interactions between edge and area effects in a heavily fragmented landscape. Ecology. 88, 96-106 (2007).

31. M. G. Betts, G. J. Forbes, A. W. Diamond, P. D. Taylor, Independent effects of fragmentation on forest songbirds: an organism-based approach. Ecological Applications. 16, 1076-1089 (2006).

32. J. M. Northrup, J. W. Rivers, Z. Yang, M. G. Betts, Synergistic effects of climate and land-use change influence broad-scale avian population declines. Global change biology (2019).

33. N. Myers, R. A. Mittermeier, C. G. Mittermeier, G. A. Da Fonseca, J. Kent, Biodiversity hotspots for conservation priorities. Nature. 403, 853 (2000).

34. M. C. Hansen et al., High-Resolution Global Maps of 21st-Century Forest Cover Change. Science. 342, 850$853(2013)$.

35. N. Gorelick et al., Google Earth Engine: Planetary-scale geospatial analysis for everyone. Remote Sensing of Environment (2017), doi:10.1016/j.rse.2017.06.031.

36. R. M. Ewers, R. K. Didham, Pervasive impact of large-scale edge effects on a beetle community. Proceedings of the National Academy of Sciences. 105, 5426-5429 (2008). 
37. P. Potapov et al., Mapping the world's intact forest landscapes by remote sensing. Ecology and Society. 13, 51 (2008).

38. D. Tilman, R. M. May, C. L. Lehman, M. A. Nowak, Habitat destruction and the extinction debt. Nature. 371, 65 (1994).

39. A. Hofgaard, B. Wilmann, Plant distribution pattern across the forest-tundra ecotone: the importance of treeline position. Ecoscience. 9, 375-385 (2002).

40. J. O. Kaplan, M. Pfeiffer, J. C. Kolen, B. A. Davis, Large scale anthropogenic reduction of forest cover in Last Glacial Maximum Europe. PLoS One. 11, e0166726 (2016).

41. BirdLife International and Handbook of the Birds of the World, Bird species distribution maps of the world. Version 6.0. Available at http://datazone.birdlife.org/species/requestdis (2016), (available at http://datazone.birdlife.org/species/requestdis).

42. IUCN, The International Union for Conservation of Nature (IUCN) Red List of Threatened Species. Version 2017.3. (2017), (available at http://www.iucnredlist.org).

43. R. Mittermeier et al., Hotspots Revisited: Earth's Biologically Richest and Most Endangered Terrestrial Ecoregions: Conservation International. Sierra Madre, Cemex (2005).

44. Conservation Synthesis, Center for Applied Biodiversity Science at Conservation International, Biodiversity Hotspots Revisited, Conservation International (2011), (available at http://www.biodiversityhotspots.org/xp/Hotspots/resources/maps.xml).

45. M. E. Brooks et al., glmmTMB Balances Speed and Flexibility Among Packages for Zero-inflated Generalized Linear Mixed Modeling. The R Journal. 9, 378-400 (2017).

46. $\quad$ R Core Team, $R$ : A Language and Environment for Statistical Computing (R Foundation for Statistical Computing, Vienna, Austria, 2018; https://www.R-project.org/).

47. Y. Benjamini, Y. Hochberg, Controlling the false discovery rate: a practical and powerful approach to multiple testing. Journal of the royal statistical society. Series B (Methodological). 57, 289-300 (1995).

48. P.-C. Bürkner, others, brms: An R Package for Bayesian Multilevel Models Using Stan. Journal of Statistical Software. 80 (2017).

49. K. E. Davis, T. W. Hesketh, C. Delmer, M. A. Wills, Towards a supertree of Arthropoda: a species-level supertree of the spiny, slipper and coral lobsters (Decapoda: Achelata). PloS one. 10, e0140110 (2015).

50. A. Figueroa, A. D. McKelvy, L. L. Grismer, C. D. Bell, S. P. Lailvaux, A species-level phylogeny of extant snakes with description of a new colubrid subfamily and genus. PLoS One. 11, e0161070 (2016).

51. R. A. Pyron, F. T. Burbrink, J. J. Wiens, A phylogeny and revised classification of Squamata, including 4161 species of lizards and snakes. BMC evolutionary biology. 13, 93 (2013).

52. S. Poe et al., A phylogenetic, biogeographic, and taxonomic study of all extant species of Anolis (Squamata; Iguanidae). Systematic biology. 66, 663-697 (2017).

53. D. R. Frost et al., The amphibian tree of life. Bulletin of the American Museum of natural History, 1-291 (2006).

54. C. S. Parr et al., The encyclopedia of life v2: providing global access to knowledge about life on earth. Biodiversity Data Journal (2014). 
55. BirdLife International, IUCN Red List for birds. IUCN Red List for birds (2019), (available at http://www.birdlife.org).

56. T. Hsieh, K. Ma, A. Chao, iNEXT: an R package for rarefaction and extrapolation of species diversity (H ill numbers). Methods in Ecology and Evolution. 7, 1451-1456 (2016).

57. M. Sciaini, M. Fritsch, C. Scherer, C. E. Simpkins, NLMR and landscapetools: An integrated environment for simulating and modifying neutral landscape models in R. Methods in Ecology and Evolution. 9, 2240-2248

345 (2018).

58. L. Fahrig, Effects of habitat fragmentation on biodiversity. Annual review of ecology, evolution, and systematics. 34, 487-515 (2003).

59. M. A. Leibold et al., The metacommunity concept: a framework for multi-scale community ecology. Ecology letters. 7, 601-613 (2004).

\section{Acknowledgments}

Funding: Funding from the National Science Foundation (NSFDEB-1457837) and the College of Forestry IWFL Professorship in Forest Biodiversity Research to M.G.B. supported this

355 research.; Author contributions: M.G.B. and C.W. conceived the study, C.W., and M.G.B. analyzed the data, with original BIOFRAG methods and data curation developed by M.P., and R.E.. M.G.B. and C.W. wrote the first draft of the paper with subsequent review and editing from all other authors, who also contributed datasets to the BIOFRAG database. Competing interests: The authors declare no competing interests. Data and materials availability: All (https://figshare.com/s/6a08ad16d9762d889e48) and BIOFRAG:

https://biofrag.wordpress.com/biofrag-measuring-biodiversity-response-to-forest-fragmentation/.

\section{Supplementary Materials}

Materials and Methods

Supplementary Text

Figs. S1 to S9

Tables S1 to S9 
Figures and Tables

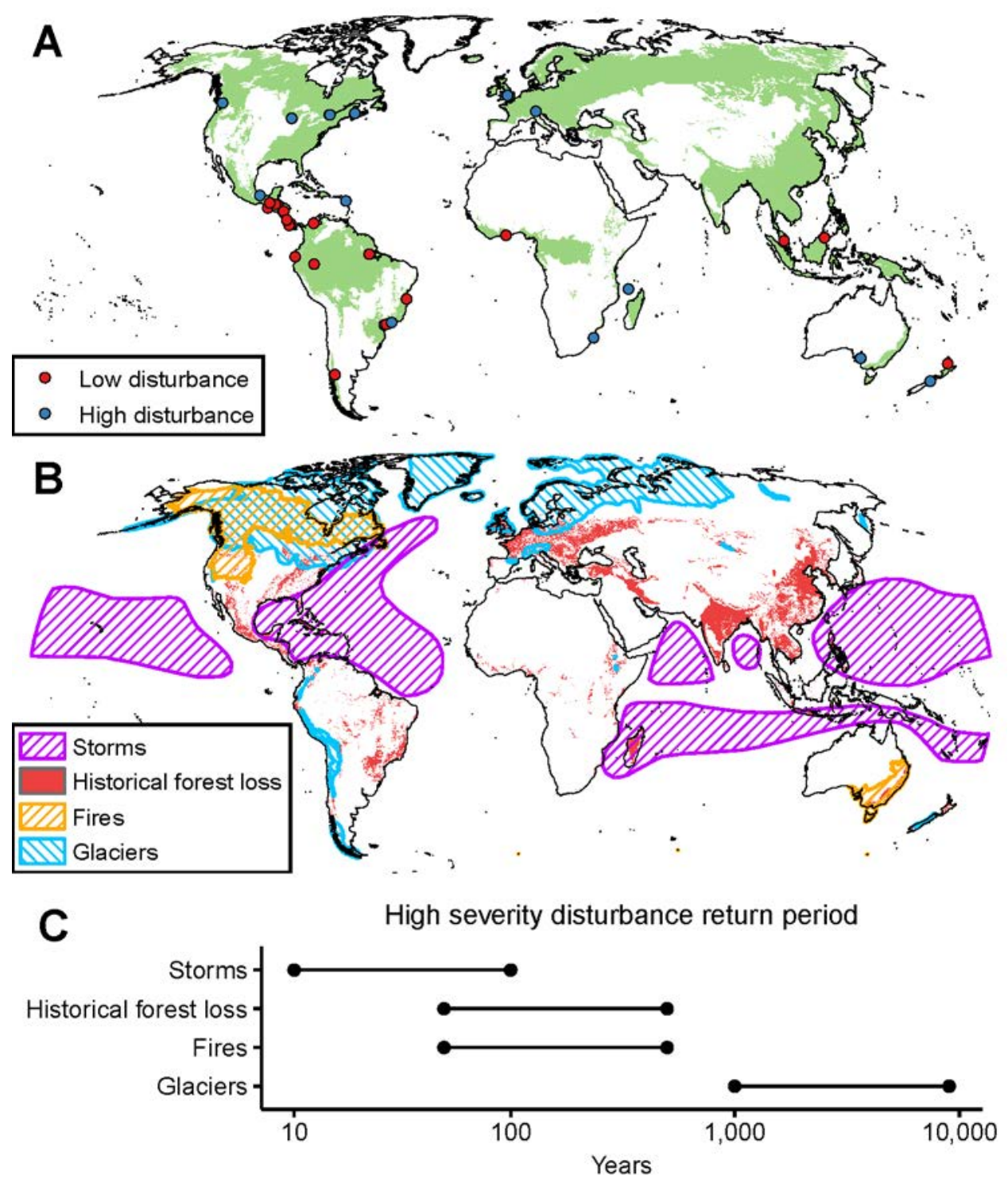

Fig. 1. Geographic distributions of sample study regions and historical disturbances. (A.) Locations of the 35 regions where the 73 datasets included in our analysis were collected. Areas that can support forests are shown in green. The BIOFRAG regions are 380 colored according to disturbance severity. (B.) Distributions of historical disturbances: tropical storms, historical (long-term) deforestation, high intensity-crown fires, and glaciation. (C.) Typical periods over which high-severity disturbances return to the same location. 

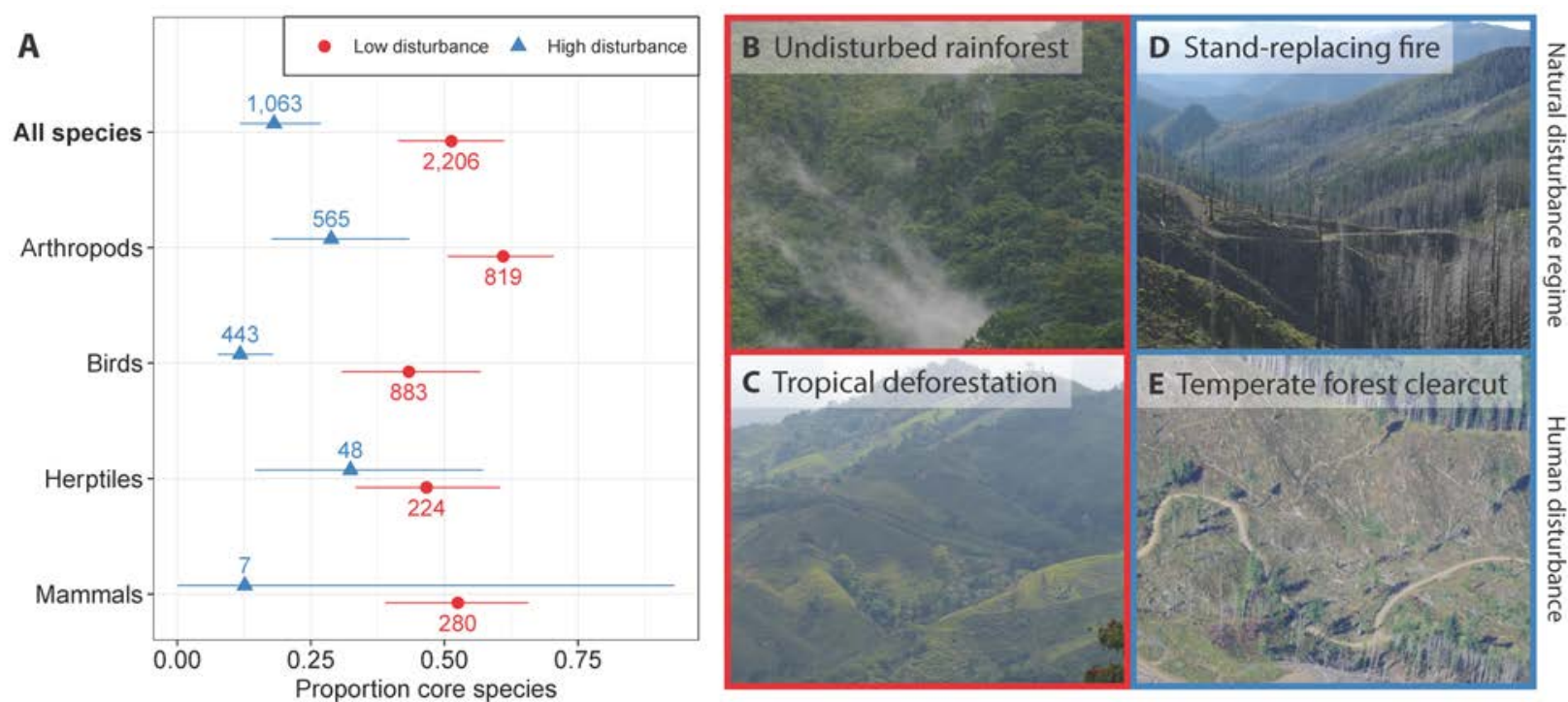

Fig. 2. (A) Estimated proportions (with $95 \%$ confidence intervals) of forest species associated with core habitat at low and high disturbance sites, according to mixedeffects logistic regression models. The binary 'disturbance' variable indicates whether or not each of the 73 BIOFRAG datasets comes from a location that has had high severity disturbances of any type (glaciation, tropical storms, crown fires, or greater than $50 \%$ historical forest loss). Numbers of species are shown beside point estimates.

(B) Tropical rainforest, undisturbed by stand-replacing disturbance and (C) tropical deforestation for pastureland versus (D) temperate forest landscape that has been disturbed by wildfire and $(E)$ temperate forest clearcuts. The extinction filter hypothesis predicts that species in disturbance-prone regions (D) should be less sensitive to habitat edges creased by anthropogenic fragmentation (E) than species that have evolved in landscapes where disturbances are rare $(B, C)$. 

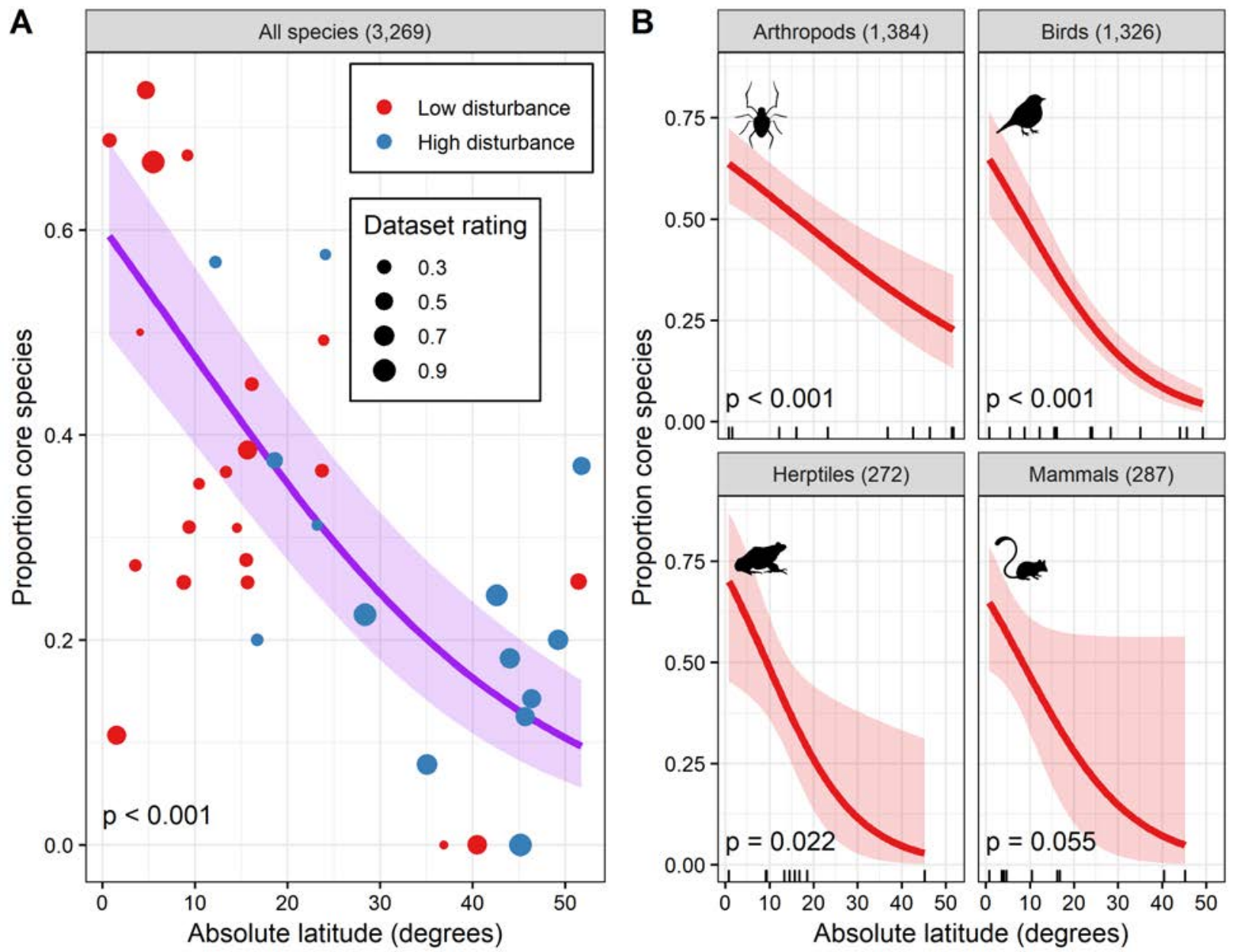

Fig. 3. Logistic regression models used to estimate the proportion of forest core species as a function of absolute latitude. In panel (A), each point shows the proportion of species classified as core within each BIOFRAG region. Point sizes indicate the dataset rating, with higher values reflecting better estimation of edge sensitivity. Point colors indicate disturbance level associated with each region. The response variable is whether or not a species was classified as preferring forest core habitat. Overall, the general pattern observed (decreasing relationship with latitude for forest species) is what one would predict if high-latitude species have evolved to cope with disturbance. $410 \quad$ Numbers of observations are shown in panel titles. Study region absolute latitudes are shown using black tick marks (panel B). All p-values were false discovery rate (FDR) adjusted to control the expected proportion of Type I errors, and taxonomic class was included as a random effect in the "All species" model. 